\title{
The epidemiology and clinical manifestations of dysexecutive syndrome in Parkinson's disease
}

\section{Roberto Ceravolo*, Cristina Pagni, Gloria Tognoni and Ubaldo Bonuccelli}

Department of Neuroscience, University of Pisa, Pisa, Italy

\section{Edited by:}

Giovanni Albani, Istituto Auxologico Italiano, IRCCS, Italy

\section{Reviewed by:}

Cristian F. Pecurariu, University of

Transylvania, Romania

Benzi Kluger, University of Colorado

Denver, USA

\section{*Correspondence:}

Roberto Ceravolo, Department of Neuroscience, University of Pisa, via Roma 67, Pisa 56126, Italy.

e-mail:r.ceravolo@neuro.med.unipi.it
This mini-review summarizes the evidence of the cognitive and behavioral features of dysexecutive syndrome in Parkinson's disease (PD). Deficits in response inhibition, setshifting, mental flexibility, and strategy have been frequently described from the earliest stages of PD, although there are inconsistencies in study findings due to the complexity of the executive function (EF) construct and methodological limitations. Behavioral disorders of PD, e.g., apathy, distractibility, perseverative behavior, and impulse-control disorders, may be viewed as the other side of dysexecutive syndrome. Despite the interrelationship between the cognitive and behavioral domains, some reports reveal that the two syndromes may be dissociated, suggesting that both aspects must be clinically assessed. EFs are widely associated with the prefrontal areas, although dysexecutive syndrome may be observed in patients with damage to other brain regions. EFs drive numerous abilities essential to daily life, such as prospective remembering and language comprehension, which may be impaired in PD subjects. Considering the impact of dysexecutive syndrome on independence and quality of life, early detection of executive impairment is crucial in the management of PD.

Keywords: Parkinson's disease, dysexecutive syndrome, executive function, neuropsychological test, cognitive impairment

\section{INTRODUCTION}

A growing body of recent studies on cognition in Parkinson's disease (PD) have indicated that different cognitive domains may be affected from the early stages of PD (Dujardin et al., 2004; Foltynie et al., 2004; Muslimovic et al., 2005; Aarsland et al., 2009a; Elgh et al., 2009; Martin et al., 2009). These include memory, language, attention, visuospatial and visuoconstructive abilities, and executive functions (EFs). Several studies have assessed the cognitive deficits in PD by using Petersen's definition of mild cognitive impairment (MCI; Petersen, 2004). The Movement Disorder Society's commissioned task force highlighted that $\mathrm{MCI}$ is common in non-demented PD subjects, with a mean prevalence of $27 \%$ (range: 19-38\%). PD-MCI is associated with increasing age, disease duration, and disease severity (Litvan et al., 2011), and may be considered to be a precursor to dementia (Aarsland et al., 1996, 2003; Hely et al., 2008).

In this regard, executive dysfunction appears to be the most pronounced impairment (Dubois and Pillon, 1997; Zgaljardic et al., 2003), although results differ depending upon the tests used and the heterogeneity of patient groups. Disorders of EF may progress to dysexecutive syndrome, a poorly defined nosological entity, which may be caused by various diseases. According to diagnostic criteria proposed by Godefroy et al. (2010), dysexecutive syndrome includes cognitive (e.g., deficits in response inhibition, set-shifting, and information generation) and/or behavioral (e.g., apathy, distractibility, perseverative behavior) alterations. In their validation study, Godefroy et al. (2010) reported a frequency of cognitive and behavioral dysexecutive syndromes of 39 and $42 \%$, respectively, in PD patients.
Some evidence highlights that executive dysfunction in nondemented PD patients predisposes to an increased impairment of daily activities (Kamei et al., 2008). Because of the impact on the patient's independence and quality of life, early detection of executive impairments is crucial in the management of PD.

\section{COGNITIVE AND BEHAVIORAL ASPECTS OF EXECUTIVE DYSFUNCTION IN PD}

"Executive function" is an umbrella term that includes different aspects of goal-directed behavior (Jurado and Rosselli, 2007). In this construct, abilities such as planning, problem-solving, top-down mechanisms of attention control, and working memory are included. There is an ongoing debate on the unitary (Duncan and Miller, 2002) versus non-unitary character of EF (Stuss and Benson, 1986; Shallice, 2002), and no gold standard neuropsychological tools have been agreed upon (Royall et al., 2002).

Although the EF construct is complex, classical "frontal" tests have been widely used in clinical practice and research on cognition in PD. These tests explore EF as a whole (e.g., Frontal Assessment Battery, Behavioral Assessment of Dysexecutive Syndrome) or some aspects of it, such as divided attention (e.g., Trail Making Test B), response inhibition (e.g., Stroop Interference Test), working memory (e.g., Digit Span forward and backward, Dual-Task paradigms), mental flexibility (e.g., Wisconsin Card Sorting Test, Verbal Fluency Tasks), and planning (e.g., Tower of London). For an explanation of these tests, see Lezak et al. (2004). Several studies have reported deficits on these tasks in early stage PD patients (Fama et al., 2000; Grace et al., 2005; Janvin et al., 2006; de Frias 
et al., 2007; Lima et al., 2008; Muslimovic et al., 2008; Siegert et al., 2008; Aarsland et al., 2009a), but the exact pattern of impairment is still under debate (Muslimovic et al., 2007; see for a review Watson and Leverenz, 2010). This impairment is often evident in timeconstraint tests, suggesting a psychomotor slowing in PD subjects (Owen et al., 1992; Robbins et al., 1994; Kamei et al., 2008). Furthermore, some reports indicate a relative sparing of performance in EFs tasks in PD subjects (Auriacombe et al., 1993; Farina et al., 2000; Cools et al., 2001; Colman et al., 2009).

Kudlicka et al. (2011) conducted a meta-analysis of the literature focusing on executive impairment in PD. In particular, they searched for studies of PD patients without dementia or depression and a Hoehn and Yahr score of I-III. Significant difficulties were found in PD subjects compared with controls across all measures of EF (i.e., verbal fluency [phonemic, semantic, and alternating], digit span backward, Wisconsin Card Sorting Test, Stroop test, Trail Making Test B). Hence, controlling for the influence of disease characteristics, it is possible to reduce the inconsistency in study findings. Nevertheless, authors highlighted many methodological limitations in EF studies; in particular, the general absence of a background formal model of EFs that specifies the various subcomponents and their assessment methods.

Classical theoretical views of EFs include the multicomponent model of Working Memory (Baddeley and Hitch, 1974, 1994) and the Supervisory Attentional System framework (Norman and Shallice, 1986). The former distinguishes four components: the central executive, which controls attention and manipulation of information, the phonological loop, and the visual sketchpad, two subcomponents involved in short-term storage of verbal and visuospatial information, and the episodic buffer. The latter postulated a supervisory system that plays a role when faced with novel situations, while the contention scheduling automatically responds to routine situations.

The debate regarding the role of the central executive and the supervisory attentional system has encouraged studies that better clarify the concept of EFs. Nevertheless, some authors do not support the concept of an undifferentiated central executive or supervisory system and propose a flexible assembly of attentive control processes (Stuss and Alexander, 2007).

Executive deficits along with visuospatial and memory and language impairments could also predict dementia in cohort studies (Jacobs et al., 1995; Mahieux et al., 1998; Levy et al., 2002; Hobson and Meara, 2004; Janvin et al., 2005). Dysexecutive syndrome has been described as a key feature of PD dementia, supporting the assumption that executive deficits might evolve into dementia. Conversely, Williams-Gray et al. (2007), in a longitudinal study of an incident population-based cohort of PD patients, found that the posterior cortically based deficits, rather than executive impairments, appeared to evolve into dementia over a 3.5-year follow-up.

It is important to consider that neuropsychiatric symptoms of PD may be associated with cognitive impairment. Apathy, depression, and anxiety are present in one-third of PD patients (Aarsland et al., 2009b). Major depression in PD has been associated with deficits in some cognitive domains, specifically memory, and EFs (Kuzis et al., 1997; Norman et al., 2002; Costa et al., 2006), presumably as a consequence of difficulty in mobilizing cognitive resources to complete tasks (Hasher and Zacks, 1979; Zakzanis et al., 1998). Varanese et al. (2011) reported that apathy, but not depression, was associated with specific disorders of recall and EFs in PD subjects. The authors highlighted the specific impairment in generating new, efficient cognitive strategies, according to the model of "cognitive inertia" (Levy and Dubois, 2006). Deficit of episodic memory in PD may thus be viewed as an epiphenomenon of poor strategy implementation in encoding and retrieval phases (Brønnick et al., 2011), rather than a primary disorder. They propose apathy to be an early manifestation of dysexecutive syndrome in PD (Varanese et al., 2011), according to Godefroy's criteria. Weintraub et al. (2005) pointed out that planning deficits and diminished inhibitory control, two dimensions of executive impairment in $\mathrm{PD}$, were associated with decreased motivation and increased motor slowing, respectively. Decreased psychomotor speed (bradyphrenia) and fatigue may be taken into account for their potential effect on test performance.

Although the emerging picture shows an interrelationship between cognitive and behavioral features, some reports reveal that the two syndromes may be dissociated (Eslinger and Damasio, 1985; Godefroy, 2003). This suggests that both behavioral and cognitive domains must be clinically assessed. Besides clinical judgment, the assessment of behavioral disorders is made through structured interviews using, for example, the Neuropsychiatric Inventory (Cummings et al., 1994), the Cambridge Behavioral Inventory (Wedderburn et al., 2008), the Frontal Behavioral Inventory (Kertesz et al., 1997). As previously mentioned, apathy is a frequent behavioral change in the early stages of $\mathrm{PD}$, but distractibility and perseverative behavior have also been reported (Sharpe, 1990; Ebersbach et al., 1994; MacHado et al., 2009). Recently, impulsecontrol disorders (ICDs), which PD patients may develop during dopamine (DA) replacement therapy, are being increasingly recognized in PD patients as indicative of dysexecutive syndrome.

Impulse-control disorders include different behaviors such as pathological gambling, hypersexuality, compulsive eating, compulsive hobbyism, and compulsive medication use. Studies reported an overall prevalence of 5.9-6.6\%. (Weintraub et al., 2010; Voon et al., 2011). ICDs have been associated with cognitive dysfunction. Findings suggested that PD patients with ICDs are impaired in frontal tasks (e.g., spatial planning and set-shifting), and specific neuropsychological correlates have been reported (Vitale et al., 2011). Conversely, other authors failed to find a dysexecutive basis for pathological gambling (Siri et al., 2010). Nevertheless, ICDs are also associated with personality traits (Farnikova et al., 2012), genetic susceptibility (Lee et al., 2009), and neuropsychiatric symptoms (Voon et al., 2011).

\section{NEUROBIOLOGICAL BASIS OF EXECUTIVE DEFICITS IN NON-DEMENTED PD SUBJECTS}

A number of relevant studies have demonstrated that EFs are widely associated with the prefrontal areas. Specifically, the dorsolateral prefrontal cortex is involved in working memory (Petrides, 2000) and cognitive flexibility (Milner, 1963; Goldman-Rakic, 1987), while the ventrolateral and orbital prefrontal cortex are involved in decision-making processes and acquisition and reversal of stimulus-reward association (Nauta, 1971; Rolls, 2000). Conversely, neuropsychological studies show that mediofrontal 
lesions are the basis of behavioral impairment (Eslinger and Damasio, 1985; Bechara et al., 1998). However, dysexecutive syndrome may be also observed in patients with damage to other brain regions (Morris et al., 1990; Owen, 2004).

Cognitive disabilities in PD have been associated with DA depletion in the prefrontal cortex and caudate nucleus (Roberts et al., 1994; Lewis et al., 2003; Carbon et al., 2004; Grahn et al., 2008). In this regard, the concept of corticostriatal loops (Alexander et al., 1986; Cummings, 1993; Lichter and Cummings, 2001) is a central model that highlights the functional connections between the frontal cortex and the striatum.

The spatiotemporal progression of the DA depletion moves from the putamen and the dorsal caudate nucleus and only later progresses to the more ventral parts of the striatum and to the mesocorticolimbic dopaminergic system (Leh et al., 2010). Within the caudate nucleus, DA depletion was greatest in the rostrodorsal extent of the head of the nucleus, an area connected to the dorsolateral regions of the frontal lobe (Yeterian and Pandya, 1991). Conversely, the ventral region of the caudate, connected to more ventral regions of the frontal lobe, is relatively spared in early PD.

These findings are consistent with the model of frontostriatal cognitive degeneration in PD proposed by Owen et al. (1998); see for a review Owen (2004). As these authors suggested, higher-level EFs, such as manipulation, strategies, and planning, that rely on the integrity of the dorsolateral frontal cortex, may be more susceptible than basic mnemonic functions, such as encoding and retrieval, which are assumed to depend on more ventral frontal regions (Petrides, 1994; Owen, 2000). This uneven dopaminergic loss has implications for medication effects on cognition. In fact, anti-parkinsonian drugs may differentially modulate cognitive performance, depending on the neural substrate underlying the cognitive function being tested (Gotham et al., 1988). According to the "L-DOPA overdose hypothesis in PD" (Cools et al., 2001), dopaminergic therapy improves the dorsal-caudate-related tasks, by normalizing DA levels in this severely depleted area, while it worsens the ventral-striatum-related tasks. This paradoxical effect is due to the "overdosing" of a relatively normal ventral striatum (Cools, 2006; Cools et al., 2007). This phenomenon is particularly evident in ICDs, as mentioned above.

The pattern of cognitive impairment in PD evolves according to progression of DA depletion within the striatum, which parallels the motor deficits of the disease (Owen et al., 1992, 1993).

However, on the basis of neuroimaging studies, some authors hypothesized that not only the nigrostriatal, but also the mesocortical dopaminergic substrate may play a significant role in cognitive dysfunction in PD (Monchi et al., 2007). Moreover, although a dopaminergic substrate of executive dysfunction is well recognized, other neurotransmitter systems (e.g., noradrenergic, serotoninergic, and cholinergic systems) may contribute to the cognitive dysfunction observed in PD (Grahn et al., 2008). Similarly, cortical Lewy body pathology, which can occur even in the early stages, may contribute to the development of dementia (de la Fuente-Fernández and Calne, 1996; Braak et al., 2003).

\section{EXECUTIVE FUNCTIONS IN DAILY LIFE}

Executive functions direct the sequencing and execution of complex goal-directed activities (e.g., cooking, dressing, check writing, and housework) so that EF impairment has emerged as a robust determinant of functional status and disability (Royall et al., 1998, 2000).

Executive functions drive other abilities essential to daily life, such as prospective remembering. Prospective memory (ProM) is a multifaceted function, concerned with the ability to implement intended actions in the future (Kliegel et al., 2011). Successful prospective remembering is crucial in all daily contexts (e.g., remembering to take medication). ProM is dependent on two components: a retrospective component supporting the retrieval of the intention content from long-term memory; and a prospective component involving real-time detection or recognition of prospective cues. The latter component requires a series of processes, including planning, maintaining multiple goals in working memory, and shifting attention, which are the subcomponents of EFs that are impaired early in PD. Previous findings from dual-task paradigms, which are based on ProM paradigms, showed that performance in the primary task increasingly worsened with increasing cognitive load of the secondary task (Brown and Marsden, 1991; Wu and Hallett, 2008; Ma et al., 2009; Proud and Morris, 2010).

Many investigations of ProM in PD found impairments in the prospective component of both event based tasks (i.e., the action is cued by an event; Katai et al., 2003; Kliegel et al., 2005; Whittington et al., 2006) and time-based tasks (i.e., the action is cued by time; Costa et al., 2008a; Raskin et al., 2011). A subtle ProM dysfunction has been described in individuals with untreated, newly diagnosed PD (Pagni et al., 2011). ProM deficits in PD are also related to task difficulty (Altgassen et al., 2007) and absence of test cueing (Foster et al., 2009). Kliegel et al. (2011) proposed that the processes specifically impaired in PD subjects are intention formation and intention initiation, which rely on planning and monitoring abilities. Moreover, there is some evidence that ProM performance in $\mathrm{PD}$ is associated with a low score on working memory and executive tests. These findings indicate that ProM deficits seen in PD could be due to executive impairment. Considering that ProM deficits are frequently associated with a reduced quality of life in neurological patients (Fish et al., 2010), it will be of interest to explore these aspects from the beginning of the disease.

Another interesting viewpoint of EFs in daily life is language. Sentence comprehension difficulties have been described in PD subjects. These comprehension deficits are particularly evident with syntactically complex passive sentences (i.e., sentences in which the thematic roles are not in the canonical positions, such as in passive sentences; Lieberman et al., 1992) and longer sentences (Caplan and Waters, 1999; Skeel et al., 2001; Grossman et al., 2003). Several aspects of executive functioning, such as inhibition, set-shifting, sequencing, and information-processing speed have been associated with language comprehension in PD (Hochstadt et al., 2006; Hochstadt, 2009). These results have theoretical implications regarding the functional basis of language impairment. Current views hold that there does not appear to be a language faculty totally modular and independent of EF influence.

As for treatment effect, Grossman et al. (2001) found that PD patients' performance on sentence comprehension worsened while they were off therapy, according to the overdose hypothesis. 
Similarly, PD subjects were selectively impaired in intention autonomous retrieval of a time-based ProM task when they were in the "off-state" (Costa et al., 2008b).

\section{IMPACT ON QUALITY OF LIFE}

There is a lack of knowledge about the subjective experience of executive dysfunction and the effect on quality of life. Awareness of cognitive impairment is crucial in order to provide appropriate support for patients and caregivers. Moreover, anosognosia (the lack of awareness of cognitive dysfunction) is a supportive deficit of behavioral dysexecutive syndrome (Godefroy et al., 2010).

Koerts et al. (2012) found that patients with mild-to-moderate PD were aware of their executive problems in daily life, and reported consistently more problems with respect to healthy controls. Nevertheless, authors failed to find an association between executive complaints and performance on tests measuring EFs. This is probably due to the lack of ecological validity of the classical executive tests, although other sources of bias in subjective reports have been described (e.g., the influence of mood, see Marino et al., 2009).

Some attempts have been made to reproduce the daily life situations in which EFs are required, which are generally unstructured regarding goals, strategies, and possible solutions. Koerts et al. (2011) have developed an instrument, the cognitive effort test (CET), that resembles multitasking in daily life. Controls and PD patients showed different strategic approaches on CET to parallel

\section{REFERENCES}

Aarsland, D., Andersen, K., Larsen, J. P., Lolk, A., and Kragh-Sørensen, P. (2003). Prevalence and characteristics of dementia in Parkinson disease: an 8-year prospective study. Arch. Neurol. 60, 387-392.

Aarsland, D., Brønnick, K., Larsen, J. P., Tysnes, O. B., and Alves, G. (2009a). Cognitive impairment in incident, untreated Parkinson disease: the Norwegian ParkWest study. Neurology 72, 1121-1126.

Aarsland, D., Marsh, L., and Schrag, A. (2009b). Neuropsychiatric symptoms in Parkinson's disease. Mov. Disord. 24, 2175-2186.

Aarsland, D., Tandberg, E., Larsen, J. P., and Cummings, J. L. (1996). Frequency of dementia in Parkinson disease. Arch. Neurol. 53, 538-542.

Alexander, G. E., DeLong, M. R., and Strick, P. L. (1986). Parallel organization of functionally segregated circuits linking basal ganglia and cortex. Annu. Rev. Neurosci. 9, 357-381.

Altgassen, M., Zöllig, J., Kopp, U., Mackinlay, R., and Kliegel, M. (2007). Patients with Parkinson's disease can successfully remember to execute delayed intentions. J. Int. Neuropsychol. Soc. 13, 888-892.

Auriacombe, S., Grossman, M., Carvell, S., Gollomp, S., Stern, M. B., and
Hurtig, H. I. (1993). Verbal fluNeuropsychology 7, 182-192.

Baddeley, A. D., and Hitch, G. J. (1994). Developments in the concept of working memory. Neuropsychology 8, 485-493.

Baddeley, A. D., and Hitch, G. J. (1974). "Working memory," in The Psychology of Learning and Motivation: Advances in Research and Theory ed. G. H. Bower (New York: Academic Press), 47-89.

Bechara, A., Damasio, H., Tranel, D., and Anderson, S. W. (1998). Dissociation of working memory from decision making within the human prefrontal cortex. J. Neurosci. 18, 428-437.

Braak, H., Del Tredici, K., Rüb, U., de Vos, R. A., Jansen Steur, E. N., and Braak, E. (2003). Staging of brain pathology related to sporadic Parkinson's disease. Neurobiol. Aging 24, 197-211.

Brauer, S. G., and Morris, M. E. (2010). Can people with Parkinson's disease improve dual tasking when walking? Gait Posture 31, 229-233.

Brønnick, K., Alves, G., Aarsland, D., Tysnes, O. B., and Larsen, J. P. (2011). Verbal memory in drug-naive, newly diagnosed Parkinson's disease. The retrieval deficit hypothesis revisited. Neuropsychology 25, 114-124.

Brown, R. G., and Marsden, C. D. (1991). Dual task performance and ency deficits in Parkinson's disease.

task execution versus sequential task execution. In this sense, PD patients, especially those with moderate PD, seem to take their psychomotor speed retardation into consideration when planning and executing tasks.

From a rehabilitation perspective, $\mathrm{PD}$ patients may take advantage of cognitive training (Sinforiani et al., 2004; Brauer and Morris, 2010; París et al., 2011; Calleo et al., 2012), although very few studies are available. Interventions, such as goal-management training (Levine et al., 2000), in which subjects were trained to explore the most useful strategies to comply with various tasks, could be successfully applied. In this regard, Costa et al. (2012) argued that interventions focusing on shifting abilities (e.g., dualtasks and switching tasks) may be useful, considering that these abilities are a subprocesses of other important functions (such as ProM and language comprehension abilities) in early impaired PD subjects.

\section{CONCLUSION}

In summary, the general picture emerging from the available literature reveals that dysexecutive syndrome in PD may have different cognitive and behavioral features. Formal test-based assessments might be able to evaluate the different executive processes. Questionnaires are useful for the assessment and follow-up of behavioral disorders. A correct assessment of both the cognitive and behavioral domains is also crucial to selecting the best treatment options.

processing resources in normal subjects and patients with Parkinson's disease. Brain 114, 215-231.

Calleo, J., Burrows, C., Levin, H., Marsh L., Lai, E., and York, M. K. (2012). Cognitive rehabilitation for executive dysfunction in Parkinson's disease: application and current directions. Parkinsons Dis. 2012, 512892.

Caplan, D., and Waters, G. S. (1999). Verbal working memory and sentence comprehension. Behav. Brain Sci. 22, 77-126.

Carbon, M., Ma, Y., Barnes, A., Dhawan, V., Chaly, T., Ghilardi, M. F., et al. (2004). Caudate nucleus: influence of dopaminergic input on sequence learning and brain activation in Parkinsonism. Neuroimage 21, 1497-1507.

Colman, K. S. F., Koerts, J., van Beilen, M., Leenders, K. L., Post, W. J., and Bastiaanse, R. (2009). The impact of executive functions on verb production in patients with Parkinson's disease. Cortex 45, 930-942.

Cools, R. (2006). Dopaminergic modulation of cognitive functionimplications for L-DOPA treatment in Parkinson's disease. Neurosci. Biobehav. Rev. 30, 1-23.

Cools, R., Barker, R. A., Sahakian, B. J., and Robbins, T. W. (2001). Mechanisms of cognitive set flexibility in Parkinson's disease. Brain 124, 2503-2512.
Cools, R., Lewis, S. J., Clark, L., Barker, R. A., and Robbins, T. W. (2007). L-DOPA disrupts activity in the nucleus accumbens during reversal learning in Parkinson's disease. Neuropsychopharmacology 32, 180-189.

Costa, A., Carlesimo, G. A., and Caltagirone, C. (2012). Prospective memory functioning: a new area of investigation in the clinical neuropsychology and rehabilitation of Parkinson's disease and mild cognitive impairment. Review of evidence. Neurol. Sci. 20, 965-972.

Costa, A., Peppe, A., Caltagirone, C., and Carlesimo, G. A. (2008a). Prospective memory impairment in individuals with Parkinson's disease. Neuropsychology 22, 283-292.

Costa, A., Peppe, A., Brusa, L., Caltagirone, C., Gatto, I., and Carlesimo, G. A. (2008b). Levodopa improves time-based prospective memory in Parkinson's disease. J. Int. Neuropsychol. Soc. 14, 601-610.

Costa, A., Peppe, A., Carlesimo, G. A., Pasqualetti, P., and Caltagirone, C. (2006). Major and minor depression in Parkinson's disease: a neuropsychological investigation. Eur. J. Neurol. 13, 972-980.

Cummings, J. L. (1993). Frontalsubcortical circuits and human behavior. Arch. Neurol. 50, 873-880. 
Cummings, J. L., Mega, M., Gray, K., Rosenberg-Thompson, S., Carusi, D. A., and Gornbein, J. (1994). The Neuropsychiatric inventory: comprehensive assessment of psychopathology in dementia. Neurology 44, 2308-2314.

de Frias, C. M., Dixon, R. A., Fisher, N., and Camicioli, R. (2007). Intraindividual variability in neurocognitive speed: a comparison of Parkinson's disease and normal older adults. Neuropsychologia 45, 2499-2507.

de la Fuente-Fernández, R., and Calne, D. B. (1996). "What do Lewy bodies tell us about dementia and parkinsonism?" in Dementia with Lewy Bodies, eds R. H. Perry, I. G. McKeith, and E. K. Perry (New York, NY: Cambridge University Press), 287-301.

Dubois, B., and Pillon, B. (1997). Cognitive deficits in Parkinson's disease. J. Neurol. 244, 2-8.

Dujardin, K., Defebvre, L., Duhamel, A., Lecouffe, P., Rogelet, P., Steinling, M., et al. (2004). Cognitive and SPECT characteristics predict progression of Parkinson's disease in newly diagnosed patients. J. Neurol. 251, 1383-1392.

Duncan, J., and Miller, E. K. (2002). "Cognitive focus through adaptive neural coding in the primate prefrontal cortex," in Principles of Frontal Lobe Function eds D. T. Stuss and R. T. Knight (New York, NY: Oxford University Press), 278-291.

Ebersbach, G., Hättig, H., Schelosky, L., Wissel, J., and Poewe, W. (1994). Perseverative motor behaviour in Parkinson's disease. Neuropsychologia 32, 799-804.

Elgh, E., Domeloff, M., Linder, J., Edström, M., Stenlund, H., and Forsgren, L. (2009). Cognitive function in early Parkinson's disease: a population-based study. Eur. J. Neurol. 16, 1278-1284.

Eslinger, P. J., and Damasio, A. R. (1985). Severe disturbance of higher cognition following bilateral frontal lobe ablation: patient EVR. Neurology 35, 1731-1741.

Fama, R., Sullivan, E. V., Shear, P. K., Stein, M., Yesavage, J. A., Tinklenberg, J. R., et al. (2000). Extent, pattern, and correlates of remote memory impairment in Alzheimer's disease and Parkinson's disease. Neuropsychology 14, 265-276.

Farina, E., Gattellaro, G., Pomati, S., Magni, E., Perretti, A., Cannatà, A. P., et al. (2000). Researching a differential impairment of frontal functions and explicit memory in early Parkinson's disease. Eur. J. Neurol. 7 , 259-267.
Farnikova, K., Obereigneru, R., Kanovsky, P., and Prasko, J. (2012). Comparison of personality characteristics in Parkinson disease patients with and without impulse control disorders and in healthy volunteers. Cogn. Behav. Neurol. 25, 25-33.

Fish, J., Wilson, B. A., and Manly, T. (2010). The assessment and rehabilitation of prospective memory problems in people with neurological disorders: a review. Neuropsychol. Rehabil. 20, 161-179.

Foltynie, T., Brayne, C. E. G., Robbins, T. W., and Barker, R. A. (2004). The cognitive ability of an incident cohort of Parkinson's patients in the UK. The CamPaIGN study. Brain $127,550-560$.

Foster, E. R., McDaniel, M. A., Repovs, G., and Hershey, T. (2009). Prospective memory in Parkinson disease across laboratory and self-reported everyday performance. Neuropsychology 23, 347-358.

Godefroy, O. (2003). Frontal syndrome and disorders of executive functions. J. Neurol. 250, 1-6.

Godefroy, O., Azouvi, P., Robert, P., Roussel, M., LeGall, D., Meulemans, T., et al. (2010). Dysexecutive syndrome: diagnostic criteria and validation study. Ann. Neurol. 68, 855-864.

Goldman-Rakic, P. S. (1987). Circuitry of the frontal association cortex and its relevance to dementia. Arch. Gerontol. Geriatr. 6, 299-309

Gotham, A. M., Brown, R. G., and Marsden, C. D. (1988). "Frontal" cognitive function in patients with Parkinson's disease "on" and "off" levodopa. Brain 111, 299-321.

Grace, J., Amick, M. M., D’Abreu, A., Festa, E. K., Heindel, W. C., and Ott, B. R. (2005). Neuropsychological deficits associated with driving performance in Parkinson's and Alzheimer's disease. J. Int. Neuropsychol. Soc. 11, 766-775.

Grahn, J. A., Parkinson, J. A., and Owen, A. M. (2008). The cognitive functions of the caudate nucleus. Prog. Neurobiol. 86, 141-155.

Grossman, M., Cooke, A., DeVita, C., Lee, C., Alsop, D., Detre, J., et al. (2003). Grammatical and resource components of sentence processing in Parkinson's disease: an fMRI study. Neurology 60, 775-781.

Grossman, M., Glosser, G., Kalmanson, J., Morris, J., Stern, M. B., and Hurtig, H. I. (2001). Dopamine supports sentence comprehension in Parkinson's Disease. J. Neurol. Sci. 184, 123-130.
Hasher, L., and Zacks, R. T. (1979). Automatic and effortful processes in memory. J. Exp. Psychol. Gen. 108, 356-388.

Hely, M. A., Reid, W. G., Adena, M. A., Halliday, G. M., and Morris, J. G. (2008). The Sydney multicenter study of Parkinson's disease: the inevitability of dementia at 20 years. Mov. Disord. 23, 837-844.

Hobson, P., and Meara, J. (2004). Risk and incidence of dementia in a cohort of older subjects with Parkinson's disease in the United Kingdom. Mov. Disord. 19, 1043-1049.

Hochstadt, J. (2009). Set-shifting and the on-line processing of relative clauses in Parkinson's disease: results from a novel eye tracking method. Cortex 45, 991-1011.

Hochstadt, J., Nakano, H., Lieberman, P., and Friedman, J. (2006). The roles of sequencing and verbal working memory in sentence comprehension deficits in Parkinson's disease. Brain Lang. 97, 243-257.

Jacobs, D. M., Marder, K., Cote, L. J., Sano, M., Stern, Y., and Mayeux, R. (1995). Neuropsychological characteristics of preclinical dementia in Parkinson's disease. Neurology 45, 1691-1696.

Janvin, C. C., Aarsland, D., and Larsen, J. P. (2005). Cognitive predictors of dementia in Parkinson's disease: a community-based, 4-year longitudinal study. J. Geriatr. Psychiatry Neurol. 18, 149-154.

Janvin, C. C., Larsen, J. P., Aarsland, D., and Hugdahl, K. (2006). Subtypes of mild cognitive impairment in Parkinson's disease: progression to dementia. Mov. Disord. 21, 1343-1349.

Jurado, M. B., and Rosselli, M. (2007). The elusive nature of executive functions: a review of our current understanding. Neuropsychol. Rev. 17, 213-233.

Kamei, S., Hara, M., Serizawa, K., Murakami, M., Mizutani, T. Ishiburo, M., et al. (2008). Executive dysfunction using behavioral assessment of the dysexecutive syndrome in Parkinson's disease. Mov. Disord. 23, 566-573.

Katai, S., Maruyama, T., Hashimoto, T. and Ikeda, S. (2003). Event-based and time-based prospective memory in Parkinson's disease. J. Neurol. Neurosurg. Psychiatr. 74, 704-709.

Kertesz, A., Davidson, W., and Fox, H. (1997). Frontal behavioral inventory: diagnostic criteria for frontal lobe dementia. Can. J. Neurol. Sci. 24, 29-36.

Kliegel, M., Altgassen, M., Hering, A., and Rose, N. S. (2011). A process- model based approach to prospective memory impairment in Parkinson's disease. Neuropsychologia 49, 2166-2177.

Kliegel, M., Phillips, L. H., Lemke, U., and Kopp, U. A. (2005). Planning and realisation of complex intentions in patients with Parkinson's disease. J. Neurol. Neurosurg. Psychiatr. 76, 1501-1505.

Koerts, J., Van Beilen, M., Leenders, K. L., Brouwer, W. H., Tucha, L., and Tucha, O. (2012). Complaints about impairments in executive functions in Parkinson's disease: the association with neuropsychological assessment. Parkinsonism Relat. Disord. 18 , 194-197.

Koerts, J., Van Beilen, M., Tucha, O., Leenders, K. L., and Brouwer, W. H. (2011). Executive functioning in daily life in Parkinson's disease: initiative, planning and multi-task performance. PLoS ONE 6, e29254. doi:10.1371/journal.pone.0029254

Kudlicka, A., Clare, L., and Hindle, J. V. (2011). Executive functions in Parkinson's disease: systematic review and meta-analysis. Mov. Disord. 26, 2305-2315.

Kuzis, G., Sabe, L., Tiberti, C., Leiguarda, R., and Starkstein, S. E. (1997). Cognitive functions in major depression and Parkinson disease. Arch. Neurol. 54, 982-986.

Lee, J. Y., Lee, E. K., Park, S. S., Lim, J. Y., Kim, H. J., Kim, J. S., et al. (2009). Association of DRD3 and GRIN2B with impulse control and related behaviors in Parkinson's disease. Mov. Disord. 24, 1803-1810.

Leh, S. E., Petrides, M., and Strafella, A. P. (2010). The neural circuitry of executive functions in healthy subjects and Parkinson's disease. Neuropsychopharmacology 35, 70-85.

Levine, B., Robertson, I. H., Clare, L., Carter, G., Hong, J., Wilson, B. A., et al. (2000). Rehabilitation of executive functioning: an experimentalclinical validation of goal management training. J. Int. Neuropsychol. Soc. 6, 299-312.

Levy, G., Jacobs, D. M., Tang, M. X., Côté, L. J., Louis, E. D., Alfaro, B., et al. (2002). Memory and executive function impairment predict dementia in Parkinson's disease. Mov. Disord. 17, 1221-1226.

Levy, R., and Dubois, B. (2006). Apathy and functional anatomy of the prefrontal cortex-basal ganglia circuits. Cereb. Cortex 16, 916-928.

Lewis, S. J., Cools, R., Robbins, T W., Dove, A., Barker, R. A., and 
Owen, A. M. (2003). Using executive heterogeneity to explore the nature of working memory deficits in Parkinson's disease. Neuropsychologia 41, 645-654.

Lezak, M. D., Howieson, D. B., and Loring, D. W. (2004). Neuropsychological Assessment. Vol. 4. New York: Oxford University Press.

Lichter, D. G., and Cummings, J. L. (2001). Frontal-Subcortical Circuits in Psvchiatric and Neurological Disorders. New York, NY: Guilford Press.

Lieberman, P., Kako, E., Friedman, J., Tajchman, G., Feldman, L. S., and Jiminez, E. B. (1992). Speech production, syntax comprehension, and cognitive deficits in Parkinson's disease. Brain Lang. 43, 169-189.

Lima, C. F., Meireles, L. P., Fonseca, R., Castro, S. L., and Garrett, C. (2008). The Frontal Assessment Battery (FAB) in Parkinson's disease and correlations with formal measures of executive functioning. J. Neurol. 255, 1756-1761.

Litvan, I., Aarsland, D., Adler, C. H., Goldman, J. G., Kulisevsky, J., Mollenhauer, B., et al. (2011). MDS Task Force on mild cognitive impairment in Parkinson's disease: critical review of PD-MCI. Mov. Disord. 26, 1814-1824.

Ma, H. I., Hwang, W. J., and Lin, K. C. (2009). The effects of two different auditory stimuli on functional arm movement in persons with Parkinson's disease: a dual-task paradigm. Clin. Rehabil. 23, 229-237.

MacHado, L., Devine, A., and Wyatt, N. (2009). Distractibility with advancing age and Parkinson's disease. $\mathrm{Neu}$ ropsychologia 47, 1756-1764.

Mahieux, F., Fenelon, G., Flahault, A., Manifacier, M. J., Michelet, D., and Boller, F. (1998). Neuropsychological prediction of dementia in Parkinson's disease. J. Neurol. Neurosurg. Psychiatr. 64, 178-183.

Marino, S. E., Meador, K. J., Loring, D. W., Okun, M. S., Fernandez, H. H., Fessler, A. J., et al. (2009). Subjective perception of cognition is related to mood and not performance. Epilepsy Behav. 14, 459-464.

Martin, W. R., Wieler, M., Gee, M., and Camicioli, R. (2009). Temporal lobe changes in early, untreated Parkinson's disease. Mov. Disord. 24, 1949-1954.

Milner, B. (1963). Effects of different brain lesions on card sorting: the role of the frontal lobes. Arch. Neurol. 9, 100-110.

Monchi, O., Petrides, M., MejiaConstain, B., and Strafella, A. P. (2007). Cortical activity in Parkinson's disease during executive processing depends on striatal involvement. Brain 130, 233-244.

Morris, R. G., Downes, J. J., and Robbins, T. W. (1990). “The nature of the dysexecutive syndrome in Parkinson's disease," in Lines of Thinking: Reflections on the Psychology of Thought, Vol 2, eds K. J. Gilhooly, M. T. G. Keane, R. H. Logie, and G. Erdos (New York: Wiley), 247-258.

Muslimovic, D., Post, B., Speelman, J. D., and Schmand, B. (2005). Cognitive profile of patients with newly diagnosed Parkinson disease. Neurology 65, 1239-1245.

Muslimovic, D., Post, B., Speelman, J. D., Schmand, B., and de Haanm, R. J. (2008). Determinants of disability and quality of life in mild to moderate Parkinson disease. Neurology 70, 2241-2247.

Muslimovic, D., Schmand, B., Speelman, J. D., and de Haan, R. J. (2007). Course of cognitive decline in Parkinson's disease: a metaanalysis. J. Int. Neuropsychol. Soc. 13, 920-932.

Nauta, W. J. (1971). The problem of the frontal lobe: a reinterpretation. J. Psychiatr. Res. 8, 167-187.

Norman, D. A., and Shallice, T. (1986). "Attention to action: willed and automatic control of behaviour," in Consciousness and Self-Regulation: Advances in Research and Theory, eds R. J. Davidson, G. E. Shwartz, and D. Shapiro (New York: Plenum), 1-18.

Norman, S., Troster, A. I., Fields, J. A., and Brooks, R. (2002). Effects of depression and Parkinson's disease on cognitive functioning. J. Neuropsychiatry Clin. Neurosci. 14, 31-36.

Owen, A. M. (2000). The role of the lateral frontal cortex in mnemonic processing: the contribution of functional neuroimaging. Exp. Brain Res. 133, 33-43.

Owen, A. M. (2004). Cognitive dysfunction in Parkinson's disease: the role of frontostriatal circuitry. Neuroscientist 10, 525-537.

Owen, A. M., Beksinska, M., James, M., Leigh, P. N., Summers, B. A., Marsden, C. D., et al. (1993). Visuospatial memory deficits at different stages of Parkinson's disease. Neuropsychologia 31, 627-644.

Owen, A. M., Doyon, J., Dagher, A., Sadikot, A., and Evans, A. C. (1998). Abnormal basal ganglia outflow in Parkinson's disease identified with PET. Implications for higher cortical functions. Brain 121, 949-965.

Owen, A. M., James, M., Leigh, P. N., Summers, B. A., Marsden, C. D., Quinn, N. P., et al. (1992). Frontostriatal cognitive deficits at different stages of Parkinson's disease. Brain 115, 1727-1751.

Pagni, C., Frosini, D., Ceravolo, R., Giunti, G., Unti, E., Poletti, M., et al. (2011). Event-based prospective memory in newly diagnosed, drug-naive Parkinson's disease patients. J. Int. Neuropsychol. Soc. 17, 1158-1162.

París, A. P., Saleta, H. G., de la Cruz Crespo Maraver, M., Silvestre, E., Freixa, M. G., Torrellas, C. P., et al. (2011). Blind randomized controlled study of the efficacy of cognitive training in Parkinson's disease. Mov. Disord. 26, 1251-1258.

Petersen, R. C. (2004). Mild cognitive impairment as a diagnostic entity. $J$. Intern. Med. 256, 183-194.

Petrides, M. (1994). "Frontal lobes and working memory: evidence from investigations of the effects of cortical excisions in nonhuman primates," in Handbook of Neuropsychology eds F. Boller and J. Grafman (Amsterdam: Elsevier). 59-82.

Petrides, M. (2000). The role of the mid-dorsolateral prefrontal cortex in working memory. Exp. Brain Res. 133, 44-54.

Proud, E. L., and Morris, M. E. (2010). Skilled hand dexterity in Parkinson's disease: effects of adding a concurrent task. Arch. Phys. Med. Rehabil. 91, 794-799.

Raskin, S. A., Woods, S. P., Poquette, A. J., McTaggart, A. B., Sethna, J., Williams, R. C., et al. (2011). A differential deficit in time- versus event-based prospective memory in Parkinson's disease. Neuropsychology 22, 201-209.

Robbins, T. W., James, M., Owen, A. M., Lange, K. W., Lees, A. J., Leigh, P. N., et al. (1994). Cognitive deficits in progressive supranuclear palsy, Parkinson's disease, and multiple system atrophy in tests sensitive to frontal lobe dysfunction. J. Neurol. Neurosurg. Psychiatr. 57, 79-88.

Roberts, A. C., De Salvia, M. A. Wilkinson, L. S., Collins, P., Muir, J. L., Everitt, B. J., et al. (1994). 6-Hydroxydopamine lesions of the prefrontal cortex in monkeys enhance performance on an analogue of the Wisconsin Card Sort Test: possible interactions with subcortical dopamine. J. Neurosci. 14, 2531-2544.

Rolls, E. T. (2000). Précis of the brain and emotion. Behav. Brain Sci. 23, 177-191.

Royall, D. R., Cabello, M., and Polk, M. J. (1998). Executive dyscontrol: an important factor affecting the level of care received by elderly retirees. J. Am. Geriatr. Soc. 46, 1519-1524.

Royall, D. R., Chiodo, L. K., and Polk, M. J. (2000). Correlates of disability among elderly retirees with "subclinical" cognitive impairment. J. Gerontol. A Biol. Sci. Med. Sci. 55, M541-M546.

Royall, D. R., Lauterbach, E. C., Cummings, J. L., Reeve, A., Rummans, T. A., Kaufer, D. I., et al. (2002). Executive control function: a review of its promise and challenges for clinical research. A report from the Committee on Research of the American Neuropsychiatric Association. J. Neuropsychiatry Clin. Neurosci. 14, 377-405.

Shallice, T. (2002). "Fractionation of the supervisory system," in Principles of Frontal Lobe Function, eds D. T. Stuss and R. T. Knight (New York, NY: Oxford University Press), 261-277.

Sharpe, M. H. (1990). Distractibility in early Parkinson's disease. Cortex 26, 239-246.

Siegert, R. J., Weatherall, M., Taylor, K. D., and Abernethy, D. A. (2008). A meta-analysis of performance on simple span and more complex working memory tasks in Parkinson's disease. Neuropsychology 22, 450-461.

Sinforiani, E., Banchieri, L., Zucchella, C., Pacchetti, C., and Sandrini, G. (2004). Cognitive rehabilitation in Parkinson's disease. Arch. Gerontol. Geriatr. Suppl. 9, 387-391.

Siri, C., Cilia, R., De Gaspari, D., Canesi, M., Meucci, N., Zecchinelli, A. L., et al. (2010). Cognitive status of patients with Parkinson's disease and pathological gambling. J. Neurol. 257, 247-252.

Skeel, R. L., Crosson, B., Nadeau, S. E., Algina, J., Bauer, R. M., and Fennell, E. B. (2001). Basal ganglia dysfunction, working memory, and sentence comprehension in patients with Parkinson's disease. Neuropsychologia 39, 962-971.

Stuss, D. T., and Alexander, M. P. (2007). Is there a dysexecutive syndrome? Philos. Trans. R. Soc. Lond. B Biol. Sci. 29, 901-915.

Stuss, D. T., and Benson, D. F. (1986). The frontal lobes. New York, NY: Raven Press.

Varanese, S., Perfetti, B., Ghilardi, M. F., and Di Rocco, A. (2011). Apathy, but not depression, reflects inefficient cognitive strategies in Parkinson's disease. PLoS ONE 6, e17846. doi:10.1371/journal.pone.0017846

Vitale, C., Santangelo, G., Trojano, L., Verde, F., Rocco, M., Grossi, D., 
et al. (2011). Comparative neuropsychological profile of pathological gambling, hypersexuality, and compulsive eating in Parkinson's disease. Mov. Disord. 26, 830-836.

Voon, V., Mehta, A. R., and Hallett, M. (2011). Impulse control disorders in Parkinson's disease: recent advances. Curr. Opin. Neurol. 24, 324-330.

Watson, G. S., and Leverenz, J. B. (2010). Profile of cognitive impairment in Parkinson's disease. Brain Pathol. 20, 640-645.

Wedderburn, C., Wear, H., Brown, J., Mason, S. J., Barker, R. A., Hodges, J., et al. (2008). The utility of the Cambridge behavioural inventory in neurodegenerative disease. J. Neurol. Neurosurg. Psychiatr. 79, 500-503.

Weintraub, D., Koester, J., Potenza, M. N., Siderowf, A. D., Stacy, M., Voon, V., et al. (2010). Impulse control disorders in Parkinson disease: a cross-sectional study of 3090 patients. Arch. Neurol. 67, 589-595.

Weintraub, D., Moberg, P. J., Culbertson, W. C., Duda, J. E., Katz, I. R., and Stern, M. B. (2005). Dimensions of executive function in Parkinson's disease. Dement. Geriatr. Cogn. Disord. 20, 140-144.

Whittington, C. J., Podd, J., and Stewart-Williams, S. (2006). Memory deficits in Parkinson's Disease. J. Clin. Exp. Neuropsychol. 28, 738-754.

Williams-Gray, C. H., Foltynie, T., Brayne, C. E., Robbins, T. W., and Barker, R. A. (2007). Evolution of cognitive dysfunction in an incident Parkinson's disease cohort. Brain 130, 1787-1798.

Wu, T., and Hallett, M. (2008). Neural correlates of dual task performance in patients with Parkinson's disease.
J. Neurol. Neurosurg. Psychiatr. 79, 760-766.

Yeterian, E. H., and Pandya, D. N. (1991). Prefrontostriatal connections in relation to cortical architectonic organization in rhesus monkeys. J. Comp. Neurol. 312, 43-67.

Zakzanis, K. K., Leach, L., and Kaplan, E. (1998). On the nature and pattern of neurocognitive function in major depressive disorder. Neuropsychiatry Neuropsychol. Behav. Neurol. 2, 111-119.

Zgaljardic, D. J., Borod, J. C., Foldi, N. S., and Mattis, P. (2003). A behavioral sequelae of Parkinson's disease: relationship to frontostriatal circuitry. Cogn. Behav. Neurol. 16 193-210.

Conflict of Interest Statement: The authors declare that the research was conducted in the absence of any commercial or financial relationships that could be construed as a potential conflict of interest.

Received: 15 April 2012; accepted: 21 October 2012; published online: 08 November 2012.

Citation: Ceravolo R, Pagni C, Tognoni $G$ and Bonuccelli $U$ (2012) The epidemiology and clinical manifestations of dysexecutive syndrome in Parkinson's disease. Front. Neur. 3:159. doi: 10.3389/fneur.2012.00159

This article was submitted to Frontiers in Movement Disorders, a specialty of Frontiers in Neurology.

Copyright (C) 2012 Ceravolo, Pagni, Tognoni and Bonuccelli. This is an openaccess article distributed under the terms of the Creative Commons Attribution License, which permits use, distribution and reproduction in other forums, provided the original authors and source are credited and subject to any copyright notices concerning any third-party graphics etc. 